\title{
Prevalence of asymptomatic pharyngeal carriage of $\beta$-hemolytic Group A Streptococcus pyogens among school going children of age 5-12 years in Bharatpur, Nepal
}

Raza S', Kundu KK'2, Dutta SK²

'Lecturer, Department of Microbiology, Kathmandu Medical College, Kathmandu, Nepal

${ }^{2}$ Professors, Department of Microbiology, College of Medical Sciences, Bharatpur, Nepal

\section{Abstract}

Background: $\beta$ - haemolytic Group A Streptococcus pyogens infection is a common cause of bacterial pharyngitis among children. Children are the target population for pharyngitis as well as other suppurative and non-suppurative infections. Objectives: The objectives of this study are to find out the rate of asymptomatic throat carriage of Streptococcus pyogens and to study antibiotic susceptibility pattern of the isolates.

Methods: Total 106 randomly selected children between five to 12 years were included in this study. Throat swabs collected were inoculated on $5 \%$ sheep blood agar and incubated for $24-48$ hours at $37^{\circ} \mathrm{C}$. Identification of Group A Streptococcus pyogens was done by $\beta$-haemolytic colony, Bacitracin sensitivity, Co-trimoxazole resistivity and catalase negativity. Antibiotic susceptibility test was performed on Muller-Hinton agar containing $5 \%$ sheep blood by modified Kirby-Bauer disc diffusion method. Results were interpreted as per National Committee for the Clinical Standards Guidelines.

Results: Of total 106 throat swabs Group A Streptococcus pyogens was isolated in 15 (14.15\%) cases. Among the isolates seven (46.7\%) were from male children whereas eight (53.3\%) were from female children. Out of the 15 isolates $100 \%$ were sensitive to penicillin and its derivatives whereas $13.2 \%, 6.7 \%$ and $6.7 \%$ of the isolates were resistant to Erythromycin, Chloramphenicol and Ciprofloxacin respectively. Similarly Azithromycin was found to be $100 \%$ sensitive.

Conclusion: Regular screening is needed to keep the GAS infection and carrier state in check as well as to prevent from further development of complications.

Key words: $\beta$-haemolytic, GAS, Streptococcus pyogens

\section{INTRODUCTION}

I nfection caused by Streptococcus pyogens (S. pyogens) is a common cause of bacterial pharyngitis among children ${ }^{1}$. It is the leading cause of acquired heart diseases; increasingly it is the major cause of death attributed to the bacterial sepsis among both children and adults ${ }^{2}$. Children are the major reservoir of Group A Streptococcus (GAS) and are the target population for pharyngitis as well as other suppurative and non-suppurative infections. They represent the pool from which adults acquire severe invasive diseases ${ }^{3}$. Prevalence of carrier state of GAS varies according to

\section{Address for correspondence}

Md. Shahid Raza

Lecturer, Department of Microbiology

Kathmandu Medical College Teaching Hospital

Sinamangal, Kathmandu, Nepal

E-mail: sahidktm@hotmail.com geographical area, season, socioeconomic condition and age group ${ }^{4}$.

GAS is responsible for about 616 million cases of throat infection (pharyngitis, tonsillitis) worldwide per year and 111 million cases of skin infection (primary non-bullous impetigo) in children of less developed countries ${ }^{5}$.GAS are the most frequently isolated pathogens in acute pharyngitis-laryngitis cases in school aged children causing approximately $20 \%$ of pharyngitis ${ }^{6,7}$.

There is not much information available on screening of children for carriage of GAS in Nepal. Hence this study will be helpful in providing information on prevalence, distribution and antibiotic susceptibility pattern of $S$. pyogens.

\section{METHODS}

This is a cross-sectional study conducted among 106 
school children of age five to 12 years from different schools of Bharatpur, Chitwan, Nepal. The study was conducted from March 2007 to October 2007. Two throat swabs collected from each child were brought to the Department of Microbiology of College of Medical Sciences; Bharatpur for the processing .One swab was used for Gram's staining and the other for culture and sensitivity. Swab was inoculated on 5\% sheep blood agar with Bacitracin (0.04 Unit) disc and incubated at $37^{\circ} \mathrm{C}$ for 24 to 48 hours. Preliminary identification of the Streptococci was done on the basis of -haemolytic colony and Bacitracin sensitivity. A zone size $>15 \mathrm{~mm}$ was considered as sensitive ${ }^{8}$.

Further confirmation of GAS was done by Gram's staining and catalase test. Antibiotic susceptibility test (AST) was performed on Muller Hinton agar containing $5 \%$ sheep blood by modified Kirby-Bauer disc diffusion method. Antibiotics used were Penicillin $(10 \mathrm{U})$, Erythromycin $(15 \mu \mathrm{g})$, Ampicillin $(10 \mu \mathrm{g})$, Cotrimoxazole $(25 \mu \mathrm{g})$, Ciprofloxacin $(5 \mu \mathrm{g})$, Azithromycin $(15 \mu \mathrm{g})$ and Chloramphenicol $(30 \mu \mathrm{g})$. Results of AST were interpreted according to National Committee for the Clinical Standards (NCCLS) Guidelines?.

\section{RESULTS}

Out of 106 swabs studied, S. pyogens was isolated from 15 (14.5\%) samples. Among the isolates seven (46.7\%) were from males whereas eight (53.3\%) were from females. Highest rate of colonization of S. pyogens was found in the age group eight to 11 years (Table 1).

Of the 15 S. pyogens isolated, 11(73.3\%) were found to be resistant to Co-trimoxazole. Resistance to Chloramphenicol, Ciprofloxacin and Erythromycin was found in one (6.7\%), one (6.7\%) and two (13.2\%) isolates respectively. No isolates were resistant to Penicillin and its derivatives (Ampicillin), similarly $100 \%$ sensitivity was noted with Azithromycin.

\section{DISCUSSION}

Group A Streptococcus throat carriage is an important public health issue as the infection often leads to post streptococcal sequelae and individuals colonized with
GAS serve as a source for spread of infection to other individuals in the community. In our study, overall $14.15 \%$ of asymptomatic school children were found to be colonized with GAS, which is similar to the study conducted by Durmaz et al who showed $14.3 \% \mathrm{~S}$. pyogens carriage ${ }^{10}$. Similar studies have been conducted in Turkey where the rate of GAS carrier in asymptomatic school children varied from $2-46 \%{ }^{11}{ }^{12}$. Disease caused by $S$. pyogens varies through the world in accordance with the season and age group ${ }^{11}$.

The age group 8-10 years was the most susceptible group for throat carriage of GAS, followed by age group 5-7 and 11-12 years respectively. Few studies have reported the age group variation ${ }^{11}$.

Present study showed that isolates are $100 \%$ susceptible to penicillin and its derivative (Ampicillin). Resistance shown by the isolates to Cotrimoxazole, Chloramphenicol, and Erythromycin were 73.3\%, 6.7\% and $13.2 \%$ respectively. This result is similar to another study conducted in $\mathrm{Nepal}^{13}$.

Due to emergence of drug resistance, appropriate treatment for severe invasive Streptococcal infection is a major challenge in many regions of the world. Our study showed a quite high resistance rate of $73 \%$ to Cotrimoxazole which is one of the commonly prescribed drugs to treat children with respiratory diseases in Nepal. None of the isolates were found to be resistant with Penicillin and its derivatives. Similar result was observed by Dumre et al ${ }^{14}$. In Nepal penicillin derivatives are among the easily available antibiotics even in sub health post level where culture facility is not available. None of the literature has reported penicillin resistant GAS till date. We also found that $100 \%$ of the isolates were susceptible to the Azithomycin which is supported by the study conducted in Nepall ${ }^{14}$. Azithromycin is commonly prescribed drug in Nepal for respiratory tract infection. However, its high frequency of prescription and possible irrational use may give rise to resistance in future. Hence it is mandatory to screen the carriage rate of GAS and its antibiotic susceptibility pattern.

Table 1: Distribution of culture positive cases according to age \& sex.

\begin{tabular}{ccccccc}
\hline \multirow{2}{*}{$\begin{array}{c}\text { Age group } \\
\text { (Year) }\end{array}$} & $\begin{array}{c}\text { Number of } \\
\text { throat swab }\end{array}$ & $\begin{array}{c}\text { Number of S. } \\
\text { pyogens isolates }\end{array}$ & $\begin{array}{c}\text { Number of } \\
\text { throat swab }\end{array}$ & $\begin{array}{c}\text { Number of } \mathbf{S} . \\
\text { pyogens isolates }\end{array}$ & $\begin{array}{c}\text { Number of } \\
\text { throat swab }\end{array}$ & $\begin{array}{c}\text { Number of S. } \\
\text { pyogens isolates }\end{array}$ \\
$5-7$ & 20 & $2(10 \%)$ & 16 & $2(12.5 \%)$ & 36 & $4(11.11 \%)$ \\
$8-10$ & 17 & $4(23.52 \%)$ & 28 & $4(14.28 \%)$ & 45 & $8(17.77 \%)$ \\
$11-12$ & 11 & $1(9.09 \%)$ & 14 & $2(14.28 \%)$ & 25 & $3(12 \%)$ \\
Total & $\mathbf{4 8}$ & $\mathbf{7 ( ( 1 4 . 5 8 \% )}$ & $\mathbf{5 8}$ & $\mathbf{8 ( 1 3 . 7 9 \% )}$ & $\mathbf{1 0 6}$ & $\mathbf{1 5 ( 1 4 . 1 5 \% )}$ \\
\hline
\end{tabular}




\section{CONCLUSION}

The result of preliminary study highlights the importance of regular surveillance to keep GAS infection and carrier state in check. Children found to be carrier could be adequately treated with antibiotics.

\section{REFERENCES}

1. Bisno AL. Group A streptococcal infections and acute rheumatic fever. N Eng J Med.1991;325:783 $-93$.

2. Tanz RR, Shulman ST, Long SS, Pickering LK, Prober CG. Principles and Practice of Pediatric Infectious Diseases. 1st ed. New York, NY: Churchill Livingstone; 1997. p. 200-7.

3. Cockerill FR, MacDonald KL, Thompson RL, Roberon F. An outbreak of invasive group A Streptococcal diseases associated with high carriage rates of invasive clones among school aged children. JAMA. 1997;277:38-43.

4. Mandell GL, Bennett JE, Dolin R. Principle and practice on infectious diseases. 5th ed. Philadelphia: Churchill Livingstone; 2000. p. 5.

5. Ozturk CE, Yavuz T, Kaya D, Yucel M. The rate of asymptomatic throat carriage of Group A Streptococcus in School going children and associated ASO titre in Duzce Turkey. Japanese J Infect Dis. 2004;57:271-2.

6. Anathnarayan R, Paniker CKJ. Textbook of Microbiology. 7th ed. India: Orient Longman Press; 2000. p. 208-9.

7. Lloyd CAC, Jacob SE, Menon T. Pharyngeal carriage of group A Streptococci in school children in Chennai. Indian J Med Res. 2006;124:195-8.
This would further facilitate control of development of the non-suppurative sequel such as acute rheumatic fever and post Streptococcal glomerulonephritis which are debilitating and difficult to treat.

8. Colle JM, Marimon BP, Faser AG. Mackie and McCartney Practical Medical Microbiology. 14th ed. UK: Churchill Living Stone; 1996.

9. National Committee for Clinical Laboratory Standards. Performance Standards for antimicrobial disc susceptibility tests. 6th ed. PA: National Committee for Clinical Laboratory standards. 1997. p. 1-46.

10. Durmaz R, Durmaz B, Bayraktar M. Prevalence of Group A streptococcal carriers in children and clonal relatedness among isolates in Malatya, Turkey. J Clin Microbiol. 2003;41:5285-7.

11. Carapetis JR, Steer AC, Mulholland EK, Weber M. The global burden of group A streptococcal diseases. Lancet Infect Dis. 2005;5:685-94.

12. Metintas S, Kalyoncu C, Etiz S, Kiraz N, Unsal N. Prevalence of group A beta haemolytic Streptococcus carriers in primary school students of Cifteler, Turkey. Anatolia Med J.1991;13:17-27.

13. Rijal KP, Dhakal N, Shah RC, Ghimire P. Antibiotic susceptibility of Group A Streptococcus isolates from throat swab culture of school children in Pokhara, Nepal. Nepal Med Coll J. 2009;11:238-40.

14. Dumre SP, Sapkota K, Adhikari N, Joshi SK. Asymptomatic throat carriage rate and antimicrobial resistance pattern of Streptococcus pyogenes in Nepalese school children. Kathmandu Univ Med J. 2009;28:392-6 